doi:10.12662/2359-618xregea.v9i3.p98-112.2020

ARTIGOS

\section{TRANSPARÊNCIA EM PROJETOS PÚBLICOS COMO FERRAMENTA DE CONTROLE DAS OBRAS DE MOBILIDADE URBANA}

\author{
TRANSPARENCY IN PUBLIC PROJECTS AS A \\ TOOL FOR CONTROL OF URBAN MOBILITY \\ WORKS
}

\section{RESUMO}

Este estudo tem como objetivo avaliar a efetividade da transparência dos projetos de mobilidade' urbana da Administração Pública na cidade de Santa Maria. De natureza exploratória e quantitativa, o estudo fundamentou-se na análise da disponibilização de informações ao cidadão pela Administração Pública municipal sobre os projetos de mobilidade urbana da cidade. A escolha pela cidade de Santa Maria deu-se porque ela está entre as cinco maiores cidades do RS e destaca-se como a maior da região central do estado. O método utilizado foi uma pesquisa documental que se apoiou em dados secundários que foram coletados por meio de dois canais: a) pesquisa em sites oficiais do governo; e b) canais de busca sobre informações quanto aos projetos de mobilidade urbana. As evidências empíricas apontam para a inexistência da disponibilidade de informações sobre o processo de gestão dos projetos de mobilidade urbana do município.

Palavras-chaves: Transparência. Mobilidade Urbana. Projetos Públicos.

\section{ABSTRACT}

This study aims to evaluate the effectiveness of the transparency of urban mobility projects of the Public Administration in the city of Santa Maria. Of an exploratory and quantitative nature, the study was based on the analysis of the availability of information to the citizen by the Municipal Public Administration on urban mobility projects in the city. The choice for the city of Santa Maria was because it is among the five largest cities of RS and stands out as the largest in the central region of the state. The method used was a documentary research and relied on secondary data collected through two channels: a) research on official government websites; and b) search channels for information on urban mobi-
\end{abstract}


lity projects. The empirical evidence points to the inexistence of availability of information about the management process of urban mobility projects of the municipality.

Keywords: Transparency. Urban Mobility. Public Projects.

\section{INTRODUÇÃO}

A propagação de fraudes e os atos de corrupção encontram um ambiente propício quando da baixa transparência das informações dos atos da administração pública, ou seja, quanto menor for a transparência dos atos, maior a oportunidade de propagação de atos ilícitos. Sendo assim, torna-se importante a preocupação da administração pública em oportunizar meios e ferramentas para maior participação cidadã e maior transparência das informações dos atos praticados. No entanto, os efeitos das políticas de transparência tendem a ser graduais, indiretos e difusos (MICHENER, 2019).

Nesse sentido, Batista, Rocha e Santos (2020) destacam que ainda existe um longo caminho a ser percorrido para que tenhamos um efetivo fortalecimento da Lei de Acesso a Informação. $\mathrm{O}$ que se percebe é a necessidade de se buscar mecanismos eficientes de transparência a fim de buscar coibir ou, pelo menos, reduzir as práticas ilícitas que são apresentadas como normais e rotineiras pelos noticiários, uma vez que a gestão adequada dos recursos públicos é de interesse de todos. Isso não é diferente na gestão de projetos públicos.

A gestão de projetos tem-se tornado, cada vez mais, um fator relevante na gestão pública uma vez que sua utilização em alguns locais já trouxe resultados positivos e propiciou o melhoramento à Administração Pública (FURTADO; FORTUNATO; TEIXEIRA, 2011; BARRETO, 2013; MARINI; MARTINS, 2014). Logo, fica evidente a necessidade da transparência também na gestão dos projetos públicos. Mecanismos de monitoramento diários e com elevado nível de transparência podem ser uma opção facilitadora do controle social, o qual, por meio de uma maior participação, consegue uma diminuição no nível de paralisações e aditivos que os projetos públicos. Assim, quem sabe elas deixem de ser regra e passem a ser exceções. No momento, isso é algo que não vem acontecendo com os projetos públicos do Brasil. Fato esse evidenciado pelo levantamento feito pela Revista Exame (SEGALA, 2015), mediante o "anuário Exame de Infraestrutura 2015 - 2016", das 10 maiores obras de infraestrutura que estavam em execução no País, em que se verificou um aumento médio de $70 \%$ no orçamento em relação à previsão inicial.

Um dos motivos para esses problemas está na falta de um detalhamento adequado desde a concepção dos projetos, visto que muitos empreendimentos nascem condenados a passar por uma série de percalços no caminho. Um indício disso é número expressivo de empreendimentos que sofrem alterações no valor do investimento. Nos dados da revista, um em cada cinco projetos públicos no País sofre uma revisão no orçamento. Outro fator é o problema da dilatação dos prazos dos projetos, aproximadamente, $16 \%$ das obras têm seu prazo de conclusão dilatado por empecilhos ambientais, legais, técnicos ou de outra natureza (SEGALA, 2015).

Diante desse contexto, torna-se evidente a necessidade de busca por mecanismos com o objetivo de incentivar uma maior transparência na gestão de projetos, para, assim, auxiliar o cidadão a exercer seu direito e a promover um maior controle social. Entretanto, não é o simples fato de uma instituição pública tornar dados disponíveis que a faz uma organização transparente (BRAGA, 2011). Em projetos públicos, não é diferente, é necessário que haja mecanismos de transparência para que a comunidade possa participar de todas as etapas do projeto.

Dito isso, tem-se a problemática que orienta o presente trabalho: os mecanismos de transparência dos projetos públicos, oportunizados pelas organizações públicas brasileiras, são adequados para oportunizar a participação social? Para responder parcialmente a essa 
questão de pesquisa, o objetivo do trabalho foi avaliar a efetividade da transparência dos projetos de mobilidade urbana da Administração Pública na cidade de Santa Maria. Nos registros acadêmicos, a maioria das pesquisas tem abordado a importância da transparência de uma forma mais geral em relação aos atos da Administração Pública.

Nesse contexto, há artigos como o da autora Guadagnin (2011), A transparência na gestão pública, que destaca que a transparência é um requisito fundamental para a boa governança e um elo entre o Estado e a sociedade civil, pois aumenta o nível de acesso do cidadão às informações sobre os atos da gestão pública. Quanto ao método da pesquisa, pode ser considerado como documental. Foram utilizadas bases de informações que não receberam tratamento analítico. O trabalho se diferencia dos anteriores, pois ele apresenta uma abordagem que está focada na transparência em projetos públicos de mobilidade urbana. Além disso, fo- ram encontrados poucos registros acadêmicos que tratam, especificamente, sobre o tema da transparência em projetos públicos de mobilidade urbana.

\section{REFERENCIAL TEÓRICO}

Nesta seção, apresenta-se uma breve contextualização acerca dos projetos de mobilidade urbana de Santa Maria, a importância da transparência na administração pública e, por fim, as características dos projetos públicos e algumas diferenças entre a área pública e privada.

\subsection{PROJETOS DE MOBILIDADE URBANA DE SANTA MARIA}

A cidade de Santa Maria desenvolveu, em 2013, um plano diretor de mobilidade urbana (PDMU). Os trabalhos da elaboração foram desenvolvidos conforme as etapas da figura 1 .

Figura 1 - Atividades desenvolvidas no processo de elaboração do PDMU

\section{Esquema de atividades do PDMU}

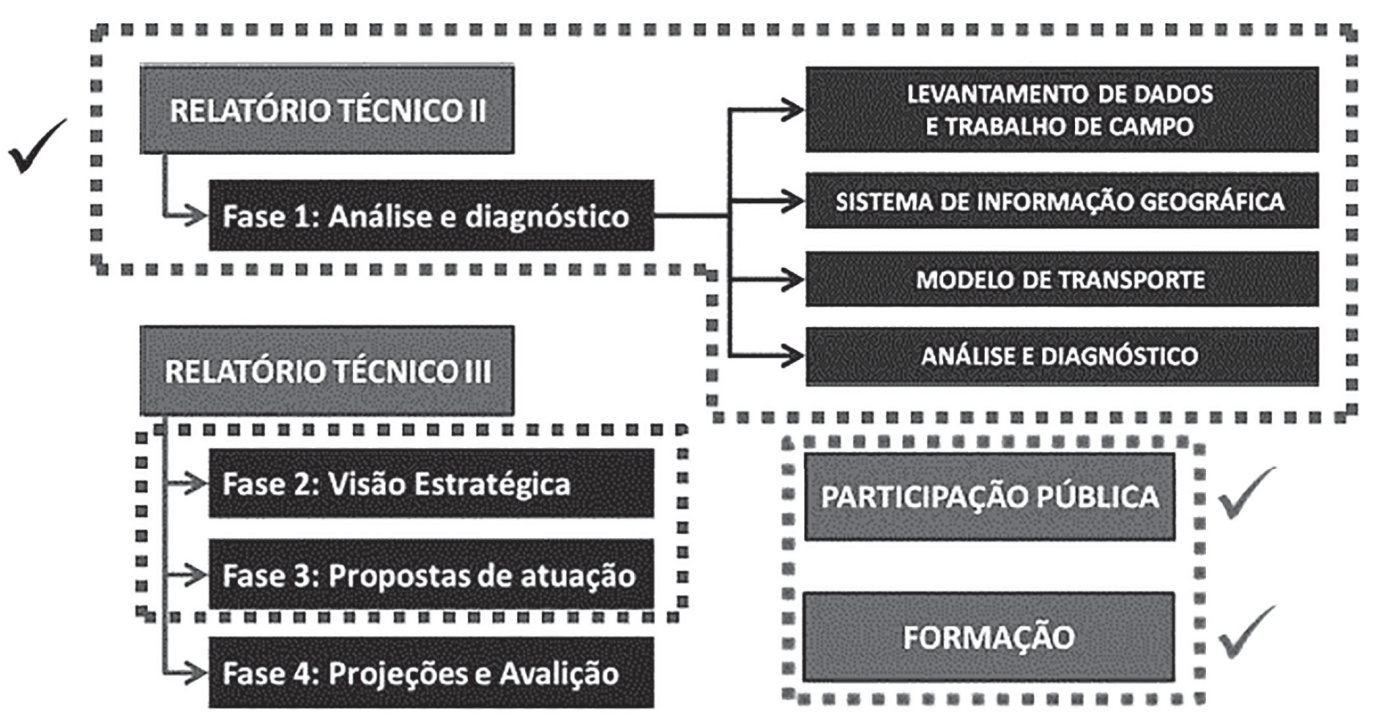

Plano Diretor de Mobilidade URBANA

Fonte: PDMU prefeitura de Santa Maria (SANTA MARIA, 2017). 
Segundo dados do PDMU, Santa Maria revela um número de deslocamento diário dos santa-marienses de, aproximadamente, 580 mil. $\mathrm{O}$ índice de mobilidade, calculado como o número de deslocamentos por pessoa por dia, atinge o valor de 2,3 deslocamentos/pessoa. Esse valor está acima de capitais do Brasil, como São Paulo que tem o índice registrado na cidade de 1,95. Esse índice se aproxima dos encontrados nas cidades do sul europeu.

Segundo os resultados apresentados pela pesquisa realizada pela equipe que desenvolveu o PDMU, quase $40 \%$ dos cidadãos de Santa Maria realizam seus deslocamentos através de automóvel e cerca de 28,2\% afirmaram que esses deslocamentos são feitos como condutor, o que revela um alto índice de uso de carro individual para o DESLOCAMENTO (SANTA MARIA, 2017). Para a definição do plano diretor de mobilidade da cidade, foram definidas algumas linhas estratégicas de atuação que são apresentadas na figura 2 .
Como objetivo para as linhas estratégicas, foram definidas as seguintes diretrizes (PDMU prefeitura de Santa Maria):

\section{Pedestres}

- Melhorar as condições dos pedestres, de forma geral, na cidade, e de forma prioritária nas vias dos bairros da cidade em que há maior presença de pedestres e ao redor dos grandes centros atratores (zonas comerciais, hospitais, escolas...).

\section{Bicicletas}

- Promover esse meio de transporte para os deslocamentos da proximidade (3-5 $\mathrm{km}$ ) e aqueles cujas condições topográficas da cidade permitam-no, estabelecendo espaços para a circulação e para o estacionamento (bicicletários e paraciclos).

Figura 2 - Linhas estratégicas do PDMU de Santa Maria

As linhas estratégicas básicas generais são:

\footnotetext{
$\checkmark$ Converter ao pedestre no principal protagonista da mobilidade na cidade

$\checkmark$ Fomentar a utilização do transporte público

$\checkmark$ Empreender atuações que ajudem a melhorar a circulação de veículos na cidade

$\checkmark$ Favorecer outros meios de transporte alternativos: bicicleta.

$\checkmark$ Organizar o espaço para o estacionamento em superfície, desestimulando uso indiscriminado do automóvel privado.

$\checkmark$ Fazer da dissuasão e a prevenção a base da disciplina circulatória na cidade

$\checkmark$ Conseguir uma distribuição de mercancias ágil e uma carga e descarga ordenada

$\checkmark$ Melhorar a segurança viária

$\checkmark$ Conseguir uma mobilidade mais respeitosa com o médio ambiente

$\checkmark$ Fazer da formação e a informação as chaves para um melhor futuro
}

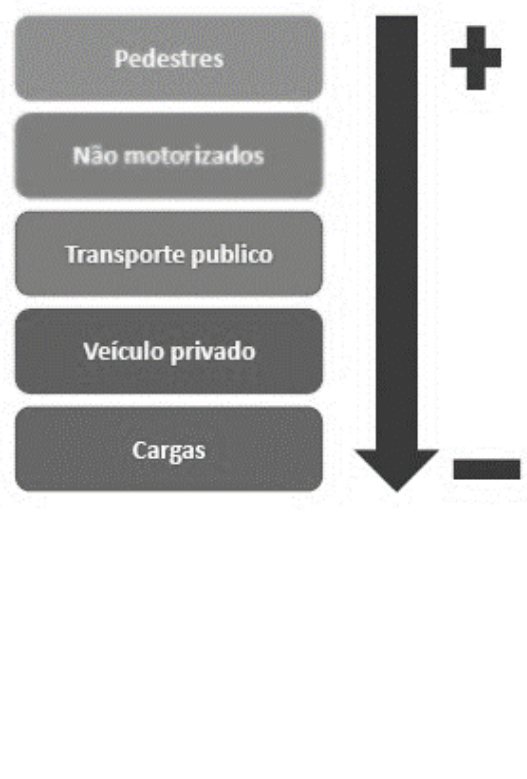

Fonte: PDMU prefeitura de Santa Maria (SANTA MARIA, 2017). 


\section{Transporte público}

- Reordenar e simplificar a rede de transporte público para fazê-la mais racional e entendível para os usuários.

- Esta nova ordenação deve ir acompanhada de melhoras na informação, operação, melhoras infraestruturas.

- Detectar corredores de transporte público com maior demanda e analisar a viabilidade de sistemas de capacidade média do Plano.

\section{Transporte privado}

- Melhorar a fluidez do tráfego e as condições de segurança nos pontos conflitivos.

- Racionalizar o uso do veículo privado e ordenar os espaços dedicados a esse modal em algumas zonas da cidade.

- Propor um novo esquema circulatório na cidade que priorize os sentidos únicos. Dessa forma, minimizam-se os pontos de conflito, melhora-se a capacidade das vias, especialmente nos cruzamentos. Essa solução também permite ganhar espaço para outros usuários da via pública, como o transporte público, os pedestres ou as bicicletas.

- Reorganizar o estacionamento em determinadas áreas da cidade para conseguir uma política coerente com a mobilidade sustentável.

\subsection{A IMPORTÂNCIA DA TRANSPARÊNCIA NA ADMINISTRAÇÃO PÚBLICA}

O Brasil tem passado, nos últimos tempos, por uma crise de valores relativos à moral e à ética. Fato que demonstra suas evidências por meio da descrença generalizada nas instituições públicas (MARTINS; VÉSPOLI, 2013). Nesse contexto, pode-se verificar uma necessidade cada vez maior quanto à promoção da transparência como forma fundamental para propiciar à condição de acesso às informações sobre os atos da administração pública. Em sua pesquisa, Pires et al. (2013) destaca a importância da prática da transparência ativa por parte dos municípios, ou seja, divulgação espontânea dos dados, das ações e dos serviços municipais ao cidadão. Os autores frisam, ainda, a necessidade de os gestores realizarem investimentos em sistemas de informações eficientes e buscarem capacitação de suas equipes para possibilitar um atendimento adequado, ágil e que atenda às expectativas e às solicitações da sociedade. Corrobora Silva (2020, p. 65), afirmando que "a transparência pública é engrenagem fundamental para coibir práticas patrimonialistas e, por conseguinte, buscar o sociodesenvolvimento dos municípios."

Essa atuação de maneira aberta torna possível o desenvolvimento de uma gestão mais transparente. Segundo Medeiros, Magalhães e Pereira (2014), para a construção de uma verdadeira democracia, torna-se necessário que haja um acesso claro e transparente das informações públicas. Os autores destacam que o acesso à informação e à transparência podem não garantir um correto funcionamento da máquina pública, mas, sem esses mecanismos, é improvável que tal atividade ocorra sequer de maneira razoável. Nesse contexto, Santos e Rocha (2019) destacam que o acesso às informações na gestão pública municipal é algo primordial, pois a transparência possibilita a promoção e a ampliação do grau de alcance de dados pelos cidadãos.

Para Nascimento (2013), o objetivo principal dessas iniciativas, que visam permitir o livre acesso às informações dos atos realizados pelas instituições públicas, é proporcionar ferramentas que facilitem a participação social do cidadão como forma de exercer a cidadania de modo mais efetivo. Para Silva e Diniz Filho (2019), é necessário que as instituições públicas disponibilizem informações para os cidadãos de acesso livre, de forma clara, prática, autêntica e segura nos seus portais institucionais de transparência. Nessa linha, Cruz (2012) complementa, afirmando que a transparência deve buscar garantir a todos os cidadãos acesso às informações que explicitam as ações a serem realizadas pelos representantes das instituições públicas, bem como, também, as que estão em 
andamento e as que foram executadas em períodos anteriores.

Essa necessidade não se diferencia na gestão de projetos, políticas públicas e atividades nas instituições públicas. Sendo assim, para viabilizar uma gestão de projetos transparente, é necessário que os projetos possibilitem a maior participação do cidadão na escolha, gestão e controle. Entretanto, isso é uma realidade ainda bastante distante em nosso país. O que se tem visto é um baixo número de organizações que disponibilizam canais de acesso a informações eficientes quanto ao andamento da gestão dos seus projetos. Em seu estudo, Santos e Kreutz (2015) destacam a baixa transparência nos projetos públicos do PAC.

A gestão pública ainda é gerida mediante a solicitação, ou seja, carece de transparência ativa. O desejável na gestão de projetos do poder público seria a divulgação, de forma espontânea e independente, de qualquer solicitação a todas as etapas do processo de elaboração e execução dos seus diferentes projetos. Esse cenário de baixa publicitação acaba por criar um ambiente propício para propagação de atos de fraudes e corrupção no setor público. Fato esse que pode ser verificado por meio dos resultados apresentados pela pesquisa da ONG Transparência Internacional (TI). Segundo o "Índice de Percepção de Corrupção 2016", que lista os países baseados em uma escala de zero (altamente corrupto) a 100 (muito transparente) o Brasil está no $79^{\circ}$ lugar entre 168 países participantes da pesquisa (TRANSPARENCY INTERNATIONAL, 2017). Logo, o resultado demonstra o elevado nível de percepção de corrupção em que o país se encontra.

Dessa forma, os dados parecem demonstrar a necessidade e a importância da transparência nas instituições públicas, pois, com a transparência, será possível que haja um estímulo à participação e ao controle social e, consequentemente, o fortalecimento do processo de participação democrático e cidadã e, assim, quem sabe reduzir os índices de corrupção nos projetos públicos.
A transparência é considerada no presente estudo como uma condição necessária para que a comunidade possa exercer seu controle social e participar do processo político da gestão dos projetos públicos, bem como de sua escolha. A falta ou a ausência de transparência tende a afetar, negativamente, a sociedade (SILVA et al., 2020). Para Jacobi (2003), é necessário que haja acessibilidade e transparência na gestão para que seja possível alcançar uma mudança significativa na participação e no controle social.

\subsection{CARACTERÍSTICAS DOS PROJETOS PÚBLICOS}

Há algum tempo, as diferenças na gestão de projetos entre o setor público e privado têm sido objeto de estudo de diversos pesquisadores. A respeito disso, Santos, Gonçalves e Dias (2012) destacam, em sua pesquisa, como fator importante que haja uma preocupação, por parte dos gestores públicos, quando da importação de mecanismos de gestão do setor privado, pois as empresas têm suas atividades voltadas para o lucro. Por outro lado, o Estado tem suas atividades voltadas ao atendimento dos interesses do cidadão.

Na visão de Wirick (2009), o setor público é um ambiente conflituoso que envolve diversos atores com interesses diferentes e que apresentam pouca preocupação com o risco. Para Valle et al. (2007), o que se destaca como o grande desafio do setor público é achar e implementar mecanismos que possibilitam viabilizar um diálogo eficaz entre os objetivos e as ferramentas de gestão de projetos utilizadas pelo setor para o atingimento de seus propósitos. Complementado essa perspectiva, Carneiro (2010) afirma que a esfera pública tem buscado implementar práticas de gerenciamento de projetos com mais intensidade e com o objetivo que ela seja uma ferramenta facilitadora para o atingimento das metas e, consequentemente, o alcance de um maior êxito na implementação das políticas públicas.

A administração pública se diferencia do setor privado justamente por suas característi- 
cas próprias e específicas e, em função disso, existe uma necessidade de adoção de práticas diferenciadas para a gestão de projetos nas organizações públicas. Neste contexto, Crawford e Helm (2009) destacam como é importante satisfazer múltiplos e imprevisíveis stakeholders como uma das especificidades do setor público. Essa diferença faz que haja uma necessidade constante de uma comunicação mais efetiva, de formas de consulta e resposta a diferentes necessidades como comunidade, usuários, clientes, consumidores, outras agências de governo, aspectos regulatórios, políticos, imprensa, setor privados e outros atores competindo pelos seus interesses, demandas e objetivos.

$\mathrm{Na}$ perspectiva de Mainardes et. al. (2010), outra especificidade das organizações públicas é a quantidade de partes interessadas que, normalmente, é superior às empresas tradicionais. Na visão do autor, esse fato se evidencia porque a administração pública envolve uma maior diversidade de atividades e também um elevado número de pessoas, grupos e organizações, os quais têm interesse direto no resultado das atividades realizadas.

Outro fator de diferenciação, destacado na literatura, é a transparência e accountability. Enquanto, no setor público, tem-se acentuada, cada dia mais, a necessidade de transparência e de prestação de contas; na área privada, não existe essa necessidade, pois as empresas existem para atender aos interesses de um indivíduo ou de um grupo. Nessa perspectiva, Costa Junior e Costa (2014) destacam a importância das instituições públicas para a questão da promoção da transparência e o estímulo ao controle social.

Nesse sentido, diferente da área privada que não tem essa necessidade, pode-se verificar a existência de uma maior preocupação dos gestores públicos com a disponibilização de canais, meios e portais de transparência para, dessa forma, poder possibilitar uma maior aproximação entre o cidadão e o Estado. Entretanto, segundo evidência de Khagram, De Renzio e Fung (2013), as relações entre transparência fiscal, participação e prestação de contas são, de maneira geral, fracas, erráticas e incompletas.

Em seus estudos Boyne (2002), realizou uma revisão de publicações de pesquisas que tiveram como foco identificar diferenças apresentadas pelas empresas privadas e órgãos públicos. O autor destaca que a existência de diferenças entre as organizações públicas e privadas tem levado ao surgimento de barreiras no que se refere à questão da transferência de técnicas de gestão do setor privado para o público. As principais hipóteses de contrastes evidenciadas nas publicações e citadas por Boyne são apresentadas no quadro 1 .

Quadro 1 - Hipóteses de contrastes entre organizações públicas e privadas

\begin{tabular}{|l|}
\hline \multicolumn{1}{|c|}{ Meio Ambiente } \\
\hline H1: Os gestores públicos trabalham em um ambiente mais complexo \\
\hline H2: As organizaçoes públicas estão mais abertas a influências ambientais \\
\hline H3: O ambiente de organismos públicos é menos estável \\
\hline H4: Os gestores públicos enfrentam pressões competitivas menos intensas \\
\hline \\
\hline H5: Os objetivos \\
\hline H6: Os gestores públicos são obrigados a exercer um maior número de objetivos \\
\hline H7: Os objetivos dos órgãos públicos são mais vagos \\
\hline \\
\hline H8: As organizações públicas são mais burocráticas \\
\hline H9: Mais burocracia está presente na tomada de decisões pelas organizações públicas \\
\hline H10: Os gerentes de agências públicas têm menos autonomia em relação aos órgãos superiores \\
\hline
\end{tabular}




\section{Valores}

H11: Os gestores do setor público são menos materialistas

H12: A motivação para servir o interesse público é maior no setor público

H13: Os gestores públicos têm comprometimento organizacional mais fraco

Fonte: (BOYNE, 2002, p. 103).

O autor destaca, em seu trabalho, o fato da existência de diferenças significativas. Elas são tanto em função dos ambientes organizacionais, dos objetivos, de suas estruturas e seus valores de gestão. Essas diferenças fazem que haja dificuldade na exportação das técnicas de gestão com sucesso de um setor para outro.

Na mesma perspectiva, Zwicker, Fettke e Loos (2010) trazem sua complementação, afirmando que as ações administrativas são afetadas diretamente pelos princípios burocráticos. Para os autores, essa passa a ser uma das principais diferenças entre a administração pública e a privada. Com o objetivo de destacar melhor as especificidades, aqueles autores desenvolveram um quadro comparativo entre os setores, que é apresentado no quadro 2. por consequência direta, interfere na sua capacidade de geração de resultados. Para o setor público, existe uma definição de suas estratégias com foco na escolha das metas e dos objetivos com base em necessidades sociais. Nas empresas, o lucro é o principal objetivo e, por consequência, suas metas, em sua maioria, utilizam medidas de lucratividade como forma de selecionar as ações.

Em se tratando de gestão de projetos, Pisa e Oliveira (2013) trazem uma visão sobre a necessidade de se levar em consideração mais algumas diferenças fundamentais entre organizações públicas e privadas. Segundo eles, devem-se considerar as seguintes diferenças: (1) o aspecto social dos projetos governamentais; (2) a obrigatoriedade da previsão dos recursos para

Quadro 2 - Características de organizações dos setores público e privado

\begin{tabular}{|l|l|l|}
\hline \multicolumn{1}{|c|}{ Características } & \multicolumn{1}{|c|}{ Privada } & \multicolumn{1}{c|}{ Pública } \\
\hline $\begin{array}{l}\text { Legalidade } \\
\text { das ações }\end{array}$ & $\begin{array}{l}\text { Ações essencialmente ilimitadas, } \\
\text { porém, alinhadas à visão e aos } \\
\text { objetivos da organização. }\end{array}$ & $\begin{array}{l}\text { Ações essencialmente limitadas a } \\
\text { leis e a regulamentos (princípio da } \\
\text { legalidade) }\end{array}$ \\
\hline Controle & Mercado organização econômica & Legitimação política \\
\hline Posição de Mercado & Ambiente competitivo & $\begin{array}{l}\text { Ambiente não competitivo } \\
\text { (características de monopólio) }\end{array}$ \\
\hline $\begin{array}{l}\text { Estrutura } \\
\text { Organizacional }\end{array}$ & $\begin{array}{l}\text { Não estabelecida uma estrutura, } \\
\text { individual a cada organização. }\end{array}$ & $\begin{array}{l}\text { Estrutura hierárquica rígida, possuindo } \\
\text { linhas claras de autoridade. }\end{array}$ \\
\hline $\begin{array}{l}\text { Requisitos de } \\
\text { Documentação }\end{array}$ & $\begin{array}{l}\text { Sem exigência explícita de } \\
\text { documentação }\end{array}$ & $\begin{array}{l}\text { Todas as decisões e ocorrências devem } \\
\text { ser documentadas para efeito de } \\
\text { controle }\end{array}$ \\
\hline Segmento de Cliente & Quase sempre heterogêneo & Heterogêneo \\
\hline Gama de Produtos & Quase sempre heterogêneo & Heterogêneo \\
\hline
\end{tabular}

Fonte: (ZWICKER; FETTKE; LOOS, 2010).

Os processos de formulação de estratégias é outra questão de diferenciação entre os dois setores e é destacada por Nutt e Backoff (1993). Para eles, essa diferença tem certo impacto quanto a seu modelo de gestão o que, execução do projeto em lei, mais especificamente na Lei Orçamentária Anual (LOA); (3) a obediência à Lei 8.666/93, que regula a contratação por meio de diversas modalidades, contemplando, de modo geral, o menor preço; (4) o excesso 
de normatizações, que provoca demora na execução dos projetos; (5) a existência de diferentes órgãos de controle nas diversas esferas de governo; (6) a exigência de prestação de contas à sociedade em virtude dos princípios da transparência e accountability na governança pública.

É perceptível a existência de interesse das organizações públicas e dos avanços já conquistados, entretanto os gestores ainda não conseguem minimizar os riscos no processo de gestão de projetos nas organizações públicas em geral. Isso pode ser evidenciado facilmente por intermédio da interminável lista de obras paradas e projetos não concluídos no setor público.

\section{MÉTODO DE PESQUISA}

A pesquisa se caraterizada quanto aos procedimentos técnicos como documental, quanto à sua natureza como aplicada e quanto à abordagem do problema como quantitativa. Tem, como população ou universo, todos os projetos de mobilidade urbana da cidade de Santa Maria. Optou-se pela escolha da cidade por ser uma das maiores cidades do RS e a maior no interior do estado. Outro motivo foi porque a cidade estava com vários projetos de mobilidade em andamento e com o anúncio do governo federal, naquele ano, de cortes em obras, elas correm risco de paralisarem. Isso poderia, por consequência, acarretar um grande prejuízo para a cidade uma vez que as obras podem ficar paradas por um bom tempo. Além do atraso na sua conclusão, uma possível paralisação das obras também afeta, diretamente, o dia a dia do cidadão, uma vez que, em função das obras, faz-se necessária a utilização de trajetos alternativos que prejudicam o bom andamento do trânsito.

Quanto às etapas de coleta de dados, pode-se destacar que o procedimento foi realizado por meio de uma pesquisa documental sobre todas as informações que foram disponibilizadas publicamente pelo município, no site da prefeitura e nos sites específicos sobre projetos de mobilidade urbana, com base em arquivos públicos e documentos oficiais. Essa atividade foi realizada entre os meses de maio e junho de 2017.

Para a análise dos dados, utilizou-se o procedimento de análise de conteúdo das informações disponibilizadas pela administração pública. Essa etapa, segundo Bardin (2010), compreende um momento de intuições por parte do pesquisador, mas tem por objetivo tornar operacionais e sistematizadas as ideias iniciais. Nesta pesquisa, utilizou-se essa técnica com o intuito de produzir inferência, trabalhando com indícios e índices postos em evidência mediante a análise das informações coletadas. Esse processo consistiu em realizar três passos conforme demonstrado na figura 3.

Figura 3- Três passos de análise

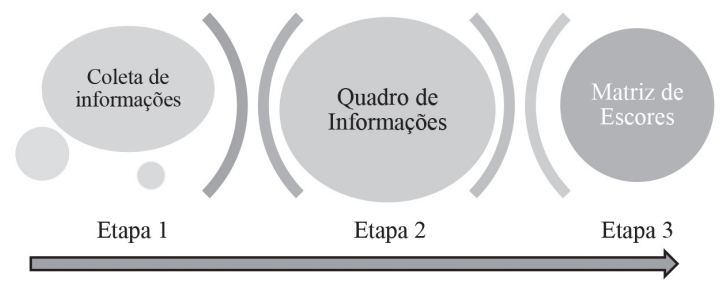

Fonte: desenvolvida pelo autor (2019).

O primeiro passo da análise deu-se por meio de uma leitura flutuante de todas as informações encontradas sobre os projetos públicos de Santa Maria que se referiam a questões de mobilidade urbana. O objetivo dessa atividade é oportunizar o pesquisador apropriar-se dos conteúdos para possibilitar maior conhecimento sobre todos os dados disponíveis referentes ao tema. Finalizada essa etapa, deu-se início ao segundo procedimento de análise que consistiu na elaboração de um quadro ilustrativo sobre as informações relevantes percebidas pelo pesquisador após análise flutuante de todos os dados coletados. Para finalizar esse segundo passo de analise, desenvolveram-se, ainda, as categorias de análise que são dimensões da transparência consideradas apropriadas ao fomento do controle social.

Por fim, passou-se para o último passo que corresponde à criação de uma matriz de es- 
cores. A matriz foi desenvolvida com a intenção de auxiliar no processo de análise dos dados e, como consequência, também possibilitar a obtenção de indícios e informações que permitam a inferência de conhecimentos relativos ao tema da presente pesquisa. Segundo Bardin (2010), realizar uma análise consiste em descobrir núcleos de sentido cuja presença ou frequência de aparição pode significar alguma coisa. Desse modo, percebe-se como coerente a utilização dessa técnica para a análise para a pesquisa.

\section{DISCUSSÃO E ANÁLISE DOS RESULTADOS}

\subsection{COLETA DE INFORMAÇÕES}

Inicialmente, foi realizada uma leitura flutuante de todas as informações encontradas nos sites oficiais do governo referente aos projetos públicos de mobilidade urbana de Santa Maria. Essa etapa possibilitou um maior conhecimento das informações disponibilizadas e facilitou identificar entre qual a quantidade de informações disponibilizadas para cada uma das variáveis analisadas. Finalizada essa etapa, foram obtidas as informações sobre os projetos com base nas variáveis mais relevantes definidas por Santos e Kreutz (2015), sendo elas: critérios de seleção dos projetos, projeto básico, projeto executivo, etapas do projeto, total de recursos alocados, recursos alocados por etapas, período de desembolso, prazo para licitação/leilão, meta conclusão execução projeto, cronograma das etapas a serem realizadas, etapas adiantadas/ atrasadas e percentual de execução projeto.

\subsection{MATRIZ DE ANÁLISE DAS INFORMAÇÕES}

O segundo passo da análise consistiu na criação de um quadro ilustrativo sobre as informações relevantes percebidas pelo pesquisador. Assim, como resultado dessa fase, obteve-se uma matriz de análise de informações dos projetos de mobilidade urbana da cidade. No presente traba- lho, utilizaram-se os fatores de Santos e Kreutz (2015) para avaliação da transparência dos projetos. Eles são critério de seleção dos projetos, etapas de planejamento dos projetos, projeção de alocação de recursos dos projetos e cronograma dos projetos. Segundo PMBOK (PROJECT MANAGEMENT INSTITUTE, 2008) ${ }^{1}$, os critérios de seleção são um método utilizado para determinar qual o projeto à organização irá selecionar entre uma quantidade de projetos possíveis. Quanto ao planejamento, cabe destacar que ele é um processo importante, pois é nessa fase que são identificadas as atividades específicas que precisam ser realizadas em um projeto. No que tange à alocação de recursos, o PMBOK destaca a importância desse processo para poder estimar o tipo e a quantidade de recursos necessários para realizar cada etapa do projeto. Quanto ao cronograma, ele frisa a necessidade do desenvolvimento desse processo para poder analisar os recursos necessários, restrições do cronograma, duração e sequência de atividades, bem como acompanhamento e controle.

As variáveis obtidas foram agrupadas dentro de cada um dos fatores com base nas dimensões definidas por Santos e Kreutz. No fator diagnóstico (A), verificou-se a existência de pesquisa prévia sobre as necessidades do município em questões de mobilidade urbana. Para o fator seleção (B), analisaram-se informações sobre os critérios de seleção dos projetos. Já no fator etapas de planejamento dos projetos (C), verificaram-se três variáveis que são: apresentação de projeto básico, existência ou não dos projetos executivos e divulgação das etapas dos projetos. No terceiro fator (D), foi verificada a disponibilização das informações referente ao total de recursos alocados, recursos alocados por etapas e período de desembolso. Por final, tem-se o fator de cronograma (E). Nele foram analisadas as variáveis prazo de licitação, metas, conclusão projetos, cronograma das etapas a serem realizadas, etapas adiantadas ou atrasadas e percentual de execução dos projetos. O resultado do agrupamento das variáveis nos fatores pode ser visto no quadro 3 .

1 Guide to the Project Management Body of Knowledge 
Quadro 3 - Matriz Informações dos projetos de mobilidade urbana de SM

\begin{tabular}{|c|c|c|c|c|c|c|c|c|c|c|c|c|c|c|}
\hline \multicolumn{15}{|c|}{ Informações dos projetos de mobilidade urbana de Santa Maria } \\
\hline \multirow{6}{*}{ 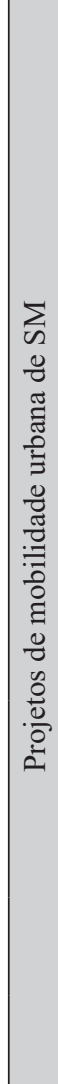 } & $\begin{array}{c}\text { Linha } \\
\text { Estratégicas }\end{array}$ & $\begin{array}{l}\text { Diagnóstico } \\
\text { (A) }\end{array}$ & $\begin{array}{l}\text { Seleção } \\
\text { (B) }\end{array}$ & $\begin{array}{r}\mathrm{f} \\
\mathrm{pr}\end{array}$ & $\begin{array}{l}\text { apa d } \\
\text { amen } \\
\text { jeto }(\end{array}$ & to do & $\begin{array}{r}\text { Proj } \\
\mathrm{R}\end{array}$ & $\begin{array}{l}\text { úo } \mathrm{Al} \\
\text { ursos }\end{array}$ & $\begin{array}{l}\text { ação } \\
\text { D) }\end{array}$ & Cror & logran & a dos & ojeto & (E) \\
\hline & 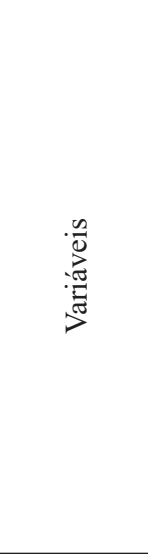 & 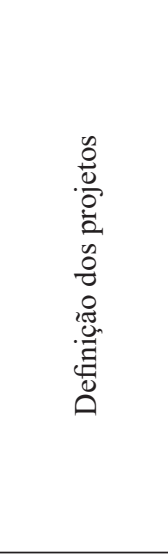 & 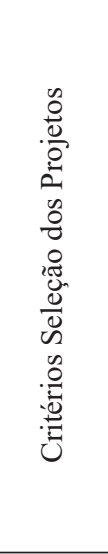 & 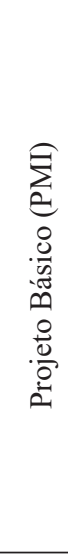 & 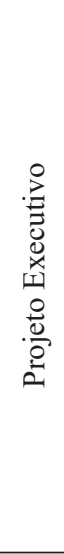 & 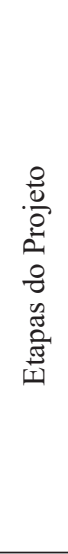 & 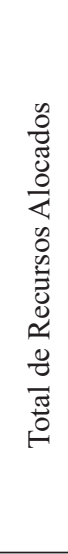 & 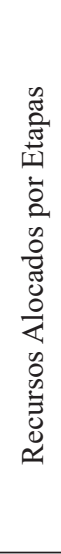 & 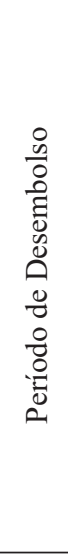 & 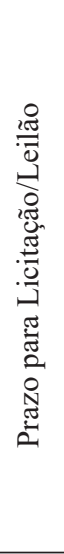 & 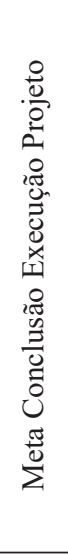 & 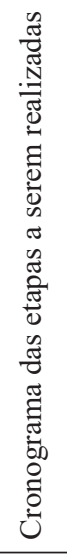 &  & 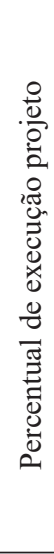 \\
\hline & Pedestres & TD & ND & ND & ND & ND & ND & ND & ND & ND & ND & ND & ND & ND \\
\hline & Bicicletas & TD & ND & ND & ND & ND & ND & ND & ND & ND & ND & ND & ND & ND \\
\hline & $\begin{array}{c}\text { Transporte } \\
\text { Público }\end{array}$ & TD & ND & ND & ND & ND & ND & ND & ND & ND & ND & ND & ND & ND \\
\hline & $\begin{array}{c}\text { Transporte } \\
\text { Privado }\end{array}$ & TD & ND & ND & ND & ND & ND & ND & ND & ND & ND & ND & ND & ND \\
\hline
\end{tabular}

Fonte: adaptado de Santos e Kreutz (2015).

O grau de disponibilidade das informações foi classificado como: ND: Não Disponível; BD: Baixa Disponibilidade; Pa.D: Parcialmente disponível ED: Elevada Disponibilidade TD: Totalmente Disponível. Esse quadro teve como objetivo servir como base para análise dos dados, pois, por meio dele, foi possível sumarizar as informações. Finalizado essa etapa, passou-se para o passo seguinte da análise. Pode-se verificar que apenas a definição dos projetos, na etapa de diagnóstico, teve todas as informações disponíveis e de fácil acesso. Todas as demais etapas de seleção, planejamento do projeto, projeção de alocação de recursos e cronograma não foi possível identificar as informações nos sites oficiais da prefeitura à época. Isso caracteriza uma baixa preocupação dos gestores e torna as informa- ções dos projetos públicas e de fácil acesso ao cidadão.

\subsection{TABELA DE ANÁLISE DOS ESCORES DOS PROJETOS DE MOBILIDADE SM}

Verificados os resultados do quadro 3, passou-se para o terceiro passo de análise que correspondeu à elaboração de tabela 1 . Teve-se como objetivo desenvolver a presente tabela para possibilitar uma análise mais objetiva a partir do uso de uma escala numérica e, assim, auxiliar no processo de análise. As pontuações utilizadas para analisar as variáveis foram: total disponibilidade (5), elevada disponibilidade (4), parcialmente disponível (3), baixa disponibilidade (2), não disponível (1). 
Tabela 1 - Matriz de Análise dos scores dos projetos de mobilidade

\begin{tabular}{|c|c|c|c|c|c|c|c|c|c|c|c|c|c|c|c|c|}
\hline \multicolumn{17}{|c|}{ Informações dos projetos de mobilidade urbana de SM } \\
\hline \multirow{6}{*}{ 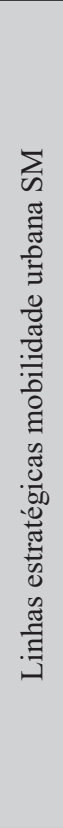 } & 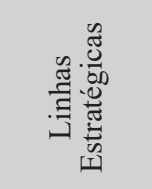 & 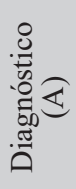 & 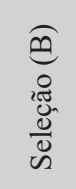 & \multicolumn{3}{|c|}{ 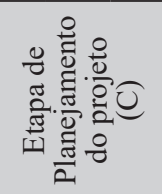 } & \multicolumn{3}{|c|}{ 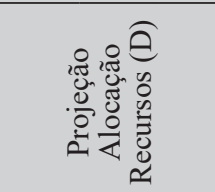 } & \multicolumn{5}{|c|}{ 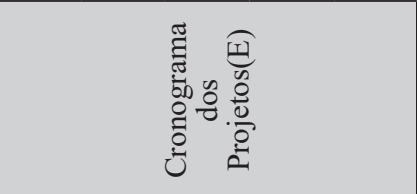 } & \multirow[b]{2}{*}{$\Sigma$} & \multirow[b]{2}{*}{ Min-Max } \\
\hline & Variáveis & 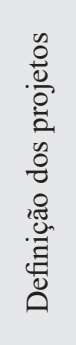 & $\begin{array}{l}n \\
0 \\
0 \\
0 \\
0 \\
0 \\
0 \\
0 \\
0 \\
0 \\
0 \\
0 \\
0 \\
0 \\
0 \\
0 \\
0 \\
0 \\
0 \\
0 \\
0\end{array}$ & $\begin{array}{l}\hat{E} \\
0 \\
0 \\
0 \\
0 \\
0 \\
0 \\
0 \\
0 \\
.0 \\
0 \\
0 \\
0\end{array}$ &  & 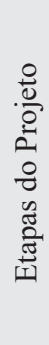 & 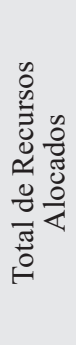 & 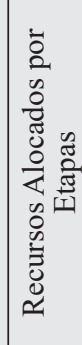 & $\begin{array}{l}\text { के } \\
0 \\
0 \\
\text { है } \\
0 \\
0 \\
0 \\
0 \\
0 \\
0 \\
\frac{0}{0} \\
0 \\
0 \\
0\end{array}$ & 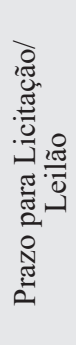 & 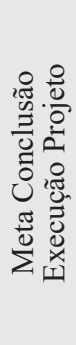 & 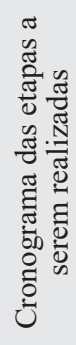 & 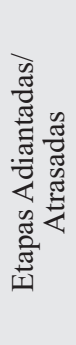 & 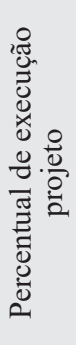 & & \\
\hline & Pedestres & 5 & 1 & 1 & 1 & 1 & 1 & 1 & 1 & 1 & 1 & 1 & 1 & 1 & 12 & $12-60$ \\
\hline & Bicicletas & 5 & 1 & 1 & 1 & 1 & 1 & 1 & 1 & 1 & 1 & 1 & 1 & 1 & 12 & $12-60$ \\
\hline & $\begin{array}{l}\text { Transporte } \\
\text { Público }\end{array}$ & 5 & 1 & 1 & 1 & 1 & 1 & 1 & 1 & 1 & 1 & 1 & 1 & 1 & 12 & $12-60$ \\
\hline & $\begin{array}{c}\text { Transporte } \\
\text { Privado }\end{array}$ & 5 & 1 & 1 & 1 & 1 & 1 & 1 & 1 & 1 & 1 & 1 & 1 & 1 & 12 & $12-60$ \\
\hline \multicolumn{2}{|r|}{$\Sigma ”$} & & 4 & 4 & 4 & 4 & 4 & 4 & 4 & 4 & 4 & 4 & 4 & 4 & & \\
\hline \multicolumn{2}{|c|}{$\Sigma$ Fatores } & 20 & 4 & \multicolumn{3}{|c|}{12} & \multicolumn{3}{|c|}{12} & \multicolumn{5}{|c|}{20} & & \\
\hline \multicolumn{2}{|c|}{$\operatorname{Min}-\operatorname{Max}$} & $4-20$ & $4-20$ & \multicolumn{3}{|c|}{$12-60$} & \multicolumn{3}{|c|}{$12-60$} & \multicolumn{5}{|c|}{$20-100$} & & \\
\hline
\end{tabular}

Fonte: adaptado de Santos e Kreutz (2015).

A tabela demostra indicadores extremamente baixos para todos os projetos de mobilidade urbana de Santa Maria. Apenas a definição dos projetos que apresentou um índice máximo de pontos, o que demostra que, nesse quesito, a prefeitura tem disponibilizado as informações. Os resultados da matriz demonstram a falta de transparência na gestão municipal quanto aos projetos de mobilidade urbana. Isso parece evidenciar uma deficiência de disponibilização de informações por parte da prefeitura, que, por consequência, dificulta também o controle e participação social do cidadão.

\subsection{DISCUSSÃO DOS RESULTADOS}

Os resultados obtidos nesta pesquisa foram analisados mediante três passos supracitados. Pode-se destacar o fator "A" (Diagnóstico dos Projetos) em que todas as linhas es- tratégicas analisadas apresentaram totalmente disponíveis. Isso é explicado pela disponibilização no site do IPLAN (Instituto de Planejamento de Santa Maria) que, em 2013, desenvolveu um plano diretor de mobilidade urbana (PDMU) para a cidade e ele consta a definição dos projetos de mobilidade urbana necessários para a cidade. $\mathrm{O}$ plano diretor de mobilidade urbana apresenta uma análise detalhada das necessidades da cidade e também uma especificação dos projetos a serem desenvolvidos para suprir essas necessidades. $\mathrm{O}$ plano diretor de mobilidade urbana foi o ponto positivo do presente estudo, pois nem todos os municípios do RS chegaram a desenvolver um plano diretor de mobilidade urbana tão detalhado como o de Santa Maria. Entretanto, não foi possível confirmar se o PDMU está sendo desenvolvido pela atual gestão do município. Essa variável se destacou, também, por ser a única que apresentou resultado positivo no estudo. Referente aos 
fatores B, C, D e E, não foi possível encontrar informações no site da prefeitura nem no site da IPLAN. Foram feitos contatos por e-mail e por telefone, mas não foi obtido sucesso.

Nos escores, os resultados não foram diferentes. O fator "A" apresentou a pontuação máxima entre todos os itens avaliados. Os demais fatores B, C, D e E apresentaram todos eles escores mais baixo possível dentro da escala. Isso aconteceu pela não disponibilização das informações por parte da prefeitura. Os resultados seguem na mesma linha de Pires et al. (2013), que, em sua pesquisa, realizaram uma análise comparativa sobre a transparência do município de Novo Hamburgo e Santa Maria. Os resultados também apontaram para uma baixa eficiência na transparência e na divulgação das informações pelo executivo municipal de Santa Maria.

\section{CONSIDERAÇÕES FINAIS}

Este estudo teve como objetivo avaliar o nível de transparência dos projetos de mobilidade urbana de Santa Maria. Para isso, foi realizada uma análise documental de dados e informações sobre os projetos disponibilizadas em sites oficiais do setor público.

Pode-se verificar que os níveis de transparência da prefeitura de Santa Maria, quanto às informações dos projetos de mobilidade urbana, são extremamente baixos. O objetivo da pesquisa foi alcançado uma vez que foi possível identificar o nível de transparência dos projetos de mobilidade da prefeitura.

Permite-se advertir que é necessário que as instituições públicas disponibilizem as informações sobre os projetos públicos com o objetivo de possibilitar uma maior participação da sociedade perante a atuação e o controle das ações das organizações públicas. Cabe mencionar que a efetiva transparência pode ser vista como uma ferramenta que tem a capacidade de potencializar a redução de abusos e a corrupção nos projetos públicos. Dessa forma, percebe-se que é importante que haja uma transparência em todos os atos das instituições públicas.
Os resultados demonstram que as ações de transparência e divulgação de informações, sobre os projetos de mobilidade urbana da cidade, não estão sendo realizadas, ou seja, parece que não existe uma preocupação por parte da gestão do município em tornar públicas as informações sobre esses projetos. Essa inexistência de transparência na gestão desses projetos públicos de mobilidade urbana do município demonstra um problema grave de gestão ou de falta de preocupação dos gestores com a transparência, fato esse que traz por consequência uma dificuldade ou, até mesmo, impossibilidade de participação da comunidade na escolha, bem como no acompanhamento da execução dos projetos.

Os resultados apresentam evidências de que os gestores, aparentemente, não têm preocupação com necessidade da disponibilização das informações referentes à escolha e ao andamento dos projetos de mobilidade urbana do município. Dessa forma, pode-se verificar que a participação social, como uma ferramenta de controle dos projetos públicos de mobilidade urbana do município, está impossibilitada uma vez que se constata a inexistência de disponibilização de informações sobre os projetos. Logo, os resultados da pesquisa possibilitam inferir que inexiste uma efetividade na transparência das informações sobre os projetos públicos de mobilidade urbana de Santa Maria.

Como análise complementar, sugerem-se investigar projetos de mobilidade urbana ou projetos de outros programas, em outros municípios e verificar se os resultados são similares.

\section{REFERÊNCIAS}

BARDIN, L. Analise de conteúdo. Lisboa: Edição 70, 2010.

BARRETO, L. C. Análise da Evolução da Metodologia de Gerenciamento de Riscos Aplicada aos Projetos Estratégicos do Governo de Minas Gerais. In: CONGRESSO CONSAD DE GESTÃO PÚBLICA, 6., 2013, Brasília. Anais [...]. Brasília, DF: Centro de Convenções Ulysses Guimarães, 2013. 
BOYNE, G. A. Public and private management: what's the difference? Journal of Management Studies, v. 39, n. 1, p. 97-122, jan. 2002 .

BRAGA, M. V. de A. A auditoria governamental como instrumento de promoção da transparência. Revista Jus Navigandi, Teresina, ano 16, n. 2900, 10 jun. 2011. Disponível em: https://jus.com.br/artigos/19318. Acesso em: 1 jun. 2017.

CARNEIRO, M. F. S. Gestão Pública: o papel do planejamento estratégico, gerenciamento de portfólio, programas e projetos e dos escritórios de projetos na modernização da gestão pública. Rio de Janeiro, RJ: Brasport, 2010.

COSTA JÚNIOR, A. G.; COSTA C. E. M. A Comunicação como Efetivação da Transparência na Gestão Pública: um estudo de caso em uma Prefeitura Municipal no interior do Nordeste. Revista Tematica, v. 10, n. 2, fev. 2014.

CRAWFORD, L. H.; HELM, J. Government and governance: The value of project management in the public sector. Project Management Journal, v. 40, n. 1, p. 73-87, Mar. 2009.

CRUZ, C. F. Transparência da gestão pública municipal: um estudo a partir dos portais eletrônicos dos maiores municípios brasileiros. Rev. Adm. Pública, Rio de Janeiro, v. 46, n.1, jan./fev. 2012.

FURTADO, M. A. P.; FORTUNATO, G.; TEIXEIRA, A. A percepção dos gestores da área pública sob a política de gerenciamento de projetos. Revista Eletrônica Sistemas \& Gestão, v. 6, n. 2, p. 167-183, 2011.

GUADAGNIN, A. A transparência da gestão pública: uma análise da sua concretização em Porto Alegre, Canoas e Novo Hamburgo. Rio Grande do Sul, RS: Universidade Federal do Rio Grande do Sul, 2011.
JACOBI, P. Educação ambiental, cidadania e sustentabilidade. Caderno de Pesquisa, n. 118, p. 189-206, 2003.

KHAGRAM, S.; DE RENZIO, P.; FUNG, A. Overview and synthesis: the political economy of fiscal transparency, participation, and accountability around the world. Open budgets: The political economy of transparency, participation, and accountability, p. 1-50, 2013.

MAINARDES, E. W. et al. Categorização por importância dos stakeholders das universidades. Revista Ibero-Americana de Estratégia, São Paulo, v. 9, n. 3, p. 5-40, set./dez. 2010.

MARINI, C.; MARTINS, H. F. Todos por Pernambuco em tempos de governança: conquistas e desafios. Recife: Instituto Publix, 2014.

MARTINS, P. L.; VÉSPOLI, B. S. O Portal da Transparência como Ferramenta para a Cidadania e o Desenvolvimento. Revista de Administração da Fatea, v. 6, n. 6, p. 93-102, jan./jul. 2013.

MEDEIROS, S. A.; MAGALHÃES, R.; PEREIRA, J. R. Lei de acesso à informação: em busca da transparência e do combate à corrupção. Revista Informação, Londrina, v. 19, n. 1, p. 55-75, jan./abr. 2014.

NASCIMENTO, L. P. A Transparência dos Portais Brasileiros de Transparência Pública: Um Estudo de Três Casos. Dissertação (mestrado) - UFRJ/ COPPE/ Programa de Revista de Administração da FATEA. RAF Revista de Administração da Fatea, v. 6, n. 6, p. 93-102, jan./jul. 2013.

NUTT, P. C.; BACKOFF, R. W. Transforming public organizations with Strategic Management and Strategic Leadership. Journal of Management, v. 19, n 2, p. 299-347, 1993.

PIRES, A. M. et al. Transparência da gestão pública municipal: um estudo dos municípios 
de Santa Maria e Novo Hamburgo / RS. Revista Estudos do CEPE, Santa Cruz do Sul, n. 38, p. 131-160, jul./dez. 2013.

PISA, B. J.; OLIVEIRA, A. G. Gestão de projetos na administração pública: um instrumento para o planejamento e desenvolvimento. In: SEMINÁRIO NACIONAL DE PLANEJAMENTO E DESENVOLVIMENTO, 1., 2013, Curitiba, PR. Anais [...]. Curitiba: PPGP/ UTFPR, 2013.

PLANO DIRETOR DE MOBILIDADE URBANA - PDMU. Disponível em: http://iplan. santamaria.rs.gov.br. Acesso em: 1 maio de 2017.

PROJECT MANAGEMENT INSTITUTE. Guia PMBOK. 4th ed. Newtown Square: Four Campus Boulevard, 2008.

SANTA MARIA (RS). Prefeitura Municipal de Santa Maria. Santa Maria, 2017. Disponível em: http://www.santamaria.rs.gov.br/. Acesso em: 9 abr. 2017.

SANTOS, P. F. A. A. S.; GONÇALVES, C. A.; DIAS, A. V. C. Implementação da Gestão de Portfólio de Projetos no Setor Público: um estudo de caso no governo de Minas Gerais. In: ENCONTRO DA ASSOCIAÇÃO NACIONAL DE PÓS-GRADUAÇÃO E PESQUISA EM ADMINISTRAÇÃO - EnANPAD, 36., 2012, Rio de Janeiro. Anais [...]. Rio de Janeiro: ANPAD, 2012.

SANTOS, C. H. S.; KREUTZ, R. R. O ciclo de vida e a transparência dos projetos do PAC no Setor Público do Brasil. Revista Instituciones y Competitividad, Peru, v. 2, n. 2, 2015.

SANTOS, L. N. dos; ROCHA, J. S. A importância da transparência para o fortalecimento da gestão pública democrática. Revista Multidisciplinar e de Psicologia, v. 13, n. 44, p. 892-904, 2019.
SEGALA, M. Anuário Exame de Infraestrutura 2015-2016. Revista Exame, São Paulo, SP, ed. 1099, ano 49, n. 19, p. 106-117, out. 2015.

SILVA, Welliton Resende. A transparência pública como fator de desenvolvimento regional no maranhão. Revista Fronteiras Plurais, v. 1, n. 2, 2020.

SILVA, M. S. da; DINIZ FILHO, J. W. de F. O comportamento do índice de transparência na gestão fiscal nos três poderes do governo federal. RAGC, v. 7, n. 29, p. 138-153, 2019.

SILVA, D. F. et al. Transparência e universalização dos Índices de Água e Esgoto no Estado do Pará, Brasil. Research, Society and Development, v. 9, n. 8, p. 1-20, 2020.

TRANSPARENCY INTERNATIONAL - TI. Índice de Percepção de Corrupção 2016. Berlin Germany, 2017. Disponível em: http://transparency.org/cpi. Acesso em: 5 jul. 2017.

WIRICK, D. W. Puclic-Sector Project Management: meeting the challenges and achieving the results. [S.l.]: John Wiles \& Sons, 2009. VALLE, A. B. et al. (2007). Fundamentos do gerenciamento de projetos. Rio de Janeiro, RJ: FGV, 2007.

ZWICKER, J.; FETTKE, P.; LLOOS, P. Business Process Maturity in Public Administrations. In: BROCKE, Jan Vom; ROSEMANN, Michael (ed.). Handbook on Business Process Management 2: Strategic Alignment, Governance, People and Culture (International Handbooks on Information Systems). Berlin: Springer, 2010. p. 369- 400. 